\title{
La Révolution et la Première République au village
}

Jean-Pierre Jessenne

\section{(2) OpenEdition}

\section{Journals}

Édition électronique

URL : https://journals.openedition.org/ahrf/2222

DOI : 10.4000/ahrf.2222

ISSN : 1952-403X

Éditeur :

Armand Colin, Société des études robespierristes

Édition imprimée

Date de publication : 1 septembre 2005

Pagination : 189-190

ISSN : 0003-4436

\section{Référence électronique}

Jean-Pierre Jessenne, «La Révolution et la Première République au village », Annales historiques de la Révolution française [En ligne], 341 | juillet-septembre 2005, mis en ligne le 27 avril 2006, consulté le 24 avril 2022. URL : http://journals.openedition.org/ahrf/2222 ; DOI : https://doi.org/10.4000/ahrf.2222

Ce document a été généré automatiquement le 24 avril 2022.

Tous droits réservés 


\title{
La Révolution et la Première République au village
}

\author{
Jean-Pierre Jessenne
}

\section{RÉFÉRENCE}

Serge Bianchi, La Révolution et la Première République au village, Paris, Éditions du C.T.H.S., 2003, 958 p., ISBN 2-7355-0529-4, 60 e.

Le titre de l'ouvrage de Serge Bianchi ne dit que partiellement l'objet et les extensions, tant chronologiques que spatiales, de cette version remaniée et mise à jour de sa thèse d'État; le sous-titre de la page de garde est en revanche parfaitement clair: Pouvoirs, votes et politisation dans les campagnes d'île-de-France, 1787-1800, Essonne et Val-de-Marne actuels. Dans ce territoire, dont la délimitation n'est dictée que par le cadre départemental des archives, ce sont bien en effet ces trois processus qui font l'objet d'une étude et d'une recomposition extraordinairement fouillées; mais ne nous y trompons pas, il ne s'agit pas seulement d'une monographie locale de plus. Grâce à une grande maîtrise de l'historiographie et des questionnements de ces dernières décennies sur les pouvoirs locaux et les engagements politiques - d'ailleurs sur plusieurs registres utilement rappelés à plusieurs étapes du livre - Serge Bianchi multiplie les cas qui constituent autant de tests d'hypothèses ou d'interprétations générales, fournies par l'histoire révolutionnaire récente. Sans nullement prétendre à l'exhaustivité j'en donnerai quelques exemples puisés dans chacune des quatre parties de l'ouvrage, découpé chronologiquement.

2 Pour la fin de l'Ancien Régime, après avoir dressé le tableau de cette société rurale déjà bien connue avec ses variantes fort différenciées, entre vallées et plateaux, selon la proximité de Paris notamment, Serge Bianchi montre des communautés villageoises le plus souvent peu institutionnalisées et aux manifestations collectives incertaines, sous la tutelle d'un État très présent, mais avec des figures du pouvoir local assez variables, sans domination manifeste d'une catégorie bien dessinée; dans ce contexte, Serge 
Bianchi propose une importante réévaluation de l'expérience des municipalités et assemblées établies selon la réforme de 1787 , qui apparaissent comme des bancs d'essai d'une collaboration administrative entre des personnels ruraux et les agents de l'État, les subdélégués au premier chef. Mais les effets socio-politiques sont paradoxaux : le rôle principal joué par les villageois les plus aisés signifie accès des ruraux à la vie publique en certains lieux, mais restriction de la participation collective là où l'assemblée communautaire semblait encore active. Au total, néanmoins, les cahiers de doléances s'avèrent peu critiques sur l'administration villageoise.

Dans ce contexte, les refontes des collectivités territoriales et de l'accès aux fonctions sous la Constituante, auxquelles est consacrée une longue deuxième partie, s'opèrent sans difficulté majeure. Serge Bianchi multiplie les indices ordinaires - découpage communal, participation électorale, déroulement $\mathrm{du}$ vote, composition des municipalités, etc - de cette greffe plutôt réussie, mais qui n'exclut pas des luttes de procédures ou de pouvoir (pour l'application du cens, la conduite des assemblées par exemple). Si on peut regretter la longueur de certains développements et la hiérarchisation parfois défaillante des apports, on se réjouira à l'inverse des études de cas très concrètes sur la mise en œuvre des institutions et les manifestations de la politisation au village; sans détailler, notons donc que chacun trouvera ainsi des moyens de comparer avec ses propres travaux dans les domaines de taux de citoyenneté, de participation... mais aussi sur des thèmes moins souvent étudiés comme l'élection des curés. Pour résumer, si là encore se dessine une forte variété des situations, notamment dans la répartition socio-professionnelle des fonctions, se dégagent les signes d'une ouverture aux affaires publiques. Elle se traduit par exemple par un fort renouvellement des détenteurs de responsabilités municipales de 1788 à 1792, par l'importance initiatique de pratiques civiques diverses tels le serment, la référence aux lois, l'engagement dans la garde nationale. En revanche, les formes de politisation plus formalisées et classiquement associées à la Révolution comme la création de sociétés politiques ou la lecture de la presse demeurent faibles jusqu'en 1792, malgré la proximité parisienne.

4 La situation change sensiblement sous la République de 1792 à 1795 à laquelle est consacrée la troisième partie. Avec un sens prononcé des nuances, Serge Bianchi examine la plupart des domaines où se manifestent les expériences politiques et sociales successives de la Première République, des subsistances aux levées d'hommes, des cultes aux fêtes et aux affaires scolaires; il montre ainsi le mélange d'engagement indéniable d'une partie des ruraux - selon des critères sociaux et territoriaux toujours complexes - , les transformations profondes des comportements qui en résultent en même temps que la prise de distance à l'égard de certaines exigences, selon des lignes de clivage qui finalement se redéploient au fil de la période, comme le montre le bon bilan des pages 544 et suivantes.

5 La quatrième partie hésite un peu entre l'étude tout à fait bienvenue du Directoire, puis du Consulat, et l'essai d'une typologie des comportements dans la longue durée. De la première démarche, on retiendra surtout un tableau balancé de l'expérience du vote censitaire et des municipalités de canton : la participation n'est pas systématiquement faible et certaines municipalités cantonales, comme celle de Limours, sont efficaces ; dans cette partie de l'île-de-France, la République directoriale au village mérite donc un bilan mitigé. Cette idée, qui traverse finalement le livre, d'une grande fluidité des comportements qui n'est pas pour autant contradictoire avec l'affirmation de la prise 
en charge rurale des affaires publiques jusque et y compris l'adhésion aux idéaux républicains, rend finalement un peu vain l'essai final de cartographie des attitudes politiques sur lequel l'auteur conclut à l'absence de géographie nette; il se dégage plutôt des profils communaux qui peuvent faire modèles: révolutionnaires, « révolutionnés » (« communes qui accueillent la Révolution sans désaveu notoire »), réfractaires.

6 Ainsi l'histoire de la Révolution et des pouvoirs au village s'enrichit d'un ouvrage important; en l'absence de synthèse et en complément à des ouvrages ayant vocation à confronter les points de vue, comme Pouvoir local et Révolution (dir. Roger Dupuy), la somme de Serge Bianchi fera partie des références régionales obligées à côté de celle de Georges Fournier par exemple. Si son cheminement parfois lent peut rebuter le lecteur impatient, le chercheur intéressé peut toujours trouver des cas significatifs se rapportant à la plupart des moments et enjeux révolutionnaires; mais on ne saurait pour autant négliger ni la pertinence des problèmes formulés, ni l'ampleur des interprétations fondamentales proposées. 